\title{
Pre-implantation exogenous progesterone and pregnancy in sheep: I. polyamines, nutrient transport, and progestamedins
}

\author{
Emily C. Hoskins ${ }^{1}$, Katherine M. Halloran ${ }^{1}$, Claire Stenhouse ${ }^{1}$, Robyn M. Moses ${ }^{1}$, Kathrin A. Dunlap', \\ Michael C. Satterfield ${ }^{1}$, Heewon Seo ${ }^{2}$, Gregory A. Johnson², Guoyao Wu ${ }^{1}$ and Fuller W. Bazer ${ }^{1 *}$ (D)
}

\begin{abstract}
Background: Administration of exogenous progesterone (P4) to ewes during the pre-implantation period advances conceptus development and implantation. This study determined effects of exogenous P4 on transport of select nutrients and pathways that enhance conceptus development. Pregnant ewes $(n=38)$ were treated with either $25 \mathrm{mg} \mathrm{P4}$ in $1 \mathrm{~mL}$ corn oil (P4, $n=18)$ or $1 \mathrm{~mL}$ corn oil alone $(\mathrm{CO}, n=20)$ from day 1.5 through day 8 of pregnancy and hysterectomized on either day 9 or day 12 of pregnancy. Endometrial expression of genes encoding enzymes for synthesis of polyamines, transporters of glucose, arginine, and glycine, as well as progestamedins was determined by RT-qPCR.

Results: On day 12 of pregnancy, conceptuses from P4-treated ewes had elongated while those from CO-treated ewes were spherical. The mRNA expression of AZIN2, an arginine decarboxylase, was lower in endometria of P4-treated than CO-treated ewes on day 9 of pregnancy. Expression of FGF10, a progestamedin, was greater in endometria of CO and P4treated ewes on day 12 of gestation in addition to P4-treated ewes necropsied on day 9 of gestation. Treatment with P4 down-regulated endometrial expression of amino acid transporter SLCTA4 on day 12 of pregnancy.

Conclusions: Results indicated that administration of exogenous P4 during the pre-implantation period advanced the expression of FGF10, which may accelerate proliferation of trophectoderm cells, but also was correlated with decreased expression of glycine and serine transporters and polyamine synthesis enzyme AZIN2. Further research with increased sample sizes may determine how differential expression affects endometrial functions and potentially embryonic loss.
\end{abstract}

Keywords: Amino acid, Endometrium, Gene expression, Polyamine, Progesterone

\section{Background}

Mechanisms responsible for establishment and maintenance of pregnancy in mammals are complex. Temporal and cell-specific regulation of expression of genes encoding for proteins is required for development of the conceptus (embryo and associated membranes), implantation, placentation, and vascularization of the uterus and conceptus for nutrient exchange [1-3]. This intricate process

\footnotetext{
* Correspondence: fbazer@cvm.tamu.edu

'Departments of Animal Science, Texas A\&M University, College Station, TX 77843-2471, USA

Full list of author information is available at the end of the article
}

often fails as, of the $20-30 \%$ of embryonic death loss in sheep, other ruminants, and most mammalian species, two-thirds of these losses occur during the periimplantation period [4-6]. Thus, research regarding embryonic mortality has focused on molecular mechanisms that positively influence conceptus development, pregnancy recognition signaling, implantation, and placentation. In sheep, the corpus luteum (CL) produces significant amounts of progesterone (P4) by day 3 of pregnancy and concentrations in maternal plasma increase to approximately $4 \mathrm{ng} / \mathrm{mL}$ on day 7 [7]. Uterine functions essential for the establishment and maintenance of 
pregnancy are regulated by $\mathrm{P} 4$, along with other hormones and growth factors, in all mammalian species studied to date. Ovine embryos enter the uterus as morulae on day 4 of pregnancy and by day 6 , the uniform cells of the morula differentiate into the inner cell mass (ICM, precursors to the embryo/fetus) and trophectoderm (Tr) cells (precursors to the chorion of the placenta). Ovine blastocysts progress from approximately $200 \mu \mathrm{m}$ in diameter on day 8 to between 400 and $900 \mu \mathrm{m}$ by day $10,10-22 \mathrm{~mm}$ by day 12 , and $25 \mathrm{~cm}$ by day 17 of pregnancy [1,8]. During elongation, ovine conceptuses secrete interferon tau (IFNT), the protein responsible for maternal recognition of pregnancy and maintenance of a functional CL to secrete progesterone (P4) [9-13]. P4 is required for successful establishment of pregnancy [14-17]; however, temporal- and cellspecific down-regulation of progesterone receptors (PGR) in the endometrial luminal epithelia (LE) and superficial glandular epithelia (sGE) is required for implantation and establishment of pregnancy [18]. Exogenous P4 therapy during the pre-implantation period of pregnancy accelerates growth and development of bovine and ovine conceptuses [19-23].

PGR are expressed in uterine LE between days 9 and 11, but down-regulation of PGR occurs after day 12 of gestation that alters the expression of genes in uterine epithelia that encode for secreted proteins and nutrient transporters responsible for accumulation of molecules, including nutrients, cytokines, and enzymes known collectively as histotroph [15, 17]. PGR expression is not down-regulated in uterine stromal cells (SC); therefore, P4 mediates it effects on uterine epithelia by inducing expression of growth factors known as progestamedins in uterine stromal cells [24]. Fibroblast growth factors 7 (FGF7) and FGF10, as well as hepatocyte growth factor (HGF) are known as progestamedins which bind to fibroblast growth factor receptor $2_{\text {IIIb }}$ and HGF receptors encoded by MET (a c-met proto-oncogene) on uterine LE, sGE, and conceptus $\operatorname{Tr}[25,26]$. The progestamedins act via their receptors in a paracrine fashion on uterine epithelial cells to stimulate secretion of histotroph and expression of transporters for nutrients. In sheep, FGF10 mRNA is expressed by endometrial SC and mesenchymal cells of the chorioallantois, while FGF7 is localized to endometrial and myometrial blood vessels [25]. HGF from uterine stromal cells mediates mesenchymalepithelial cross-talk in the uterus and conceptus [27, 28].

Expression of the mRNA for the glucose transporter SLC2A1 (solute carrier family 2 member 1) is upregulated in ovine uterine LE and SGE by $\mathrm{P} 4$. This is further stimulated by IFNT and is accompanied by a sixfold increase of glucose in the uterine lumen between days 10 and 15 of pregnancy [29]. SLC2A3 (solute carrier family 2 member 3 ), another glucose transporter, is expressed by ovine conceptus $\mathrm{Tr}$ and endoderm between days 12 and 20 of pregnancy [29]. Further, total amounts of glucose are greater in uterine flushings of ewes treated with exogenous $\mathrm{P} 4$ than those treated with corn oil (CO) during the pre-implantation period of pregnancy [30].

The gene SLC5A1 (solute carrier family 5 member 1) encodes for the sodium dependent glucose transporter and its expression increases in uterine LE, sGE and GE between days 12 and 14 of gestation, but it is localized only to uterine GE between days 16 and 20 of pregnancy [29]. SLC5A1 protein is abundant on the apical surfaces of uterine LE between days 12 and 14 of pregnancy, indicating its importance for transport during the periimplantation period of pregnancy. Further, its expression is greater in uterine LE and sGE of ewes treated with exogenous $\mathrm{P} 4$ in early pregnancy [29-31].

SLC7A1(solute carrier family 7 member 1 ) is a gene that encodes the System $\mathrm{y}^{+}$high affinity cationic amino acid transporter. Arginine is a cationic amino acid of particular importance for implantation and pregnancy, as it can be metabolized to nitric oxide (NO) that stimulates angiogenesis and vasodilation of blood vessels, as well as polyamines utilized in many cellular functions required for conceptus development [32, 33]. Arginine plays a vital role during gestation, without which intrauterine growth restriction and altered genome expression of the fetus occurs [34]. In pregnant ewes, total amounts of arginine and histidine in uterine flushings increase 8 - to 25 -fold between days 10 and 16 of pregnancy $[35,36]$. Treatment with exogenous $\mathrm{P} 4$ during the peri-implantation period of pregnancy increases the amount of arginine recovered from the uterine lumen on day 9 of pregnancy [30].

The gene SLC6A9 (solute carrier family 6 member 9) encodes for the sodium and chloride dependent glycine transporter while SLC1A4 (solute carrier family $1 \mathrm{mem}$ ber 4) encodes for an alanine/serine/cysteine/threonine transporter. Glycine and serine are the most abundant amino acids in uterine flushings from pregnant ewes [35]. Serine is the precursor for glycine that is metabolized to formate in one carbon metabolism, which is important for nucleotide synthesis. Further, serine affects protein synthesis, $\mathrm{Ca}^{2+}$ homeostasis, and the immune system, and acts as a neurotransmitter in the central nervous system [37]. There are no reports of expression of mRNAs for glycine or serine transporters by cells within the uterus of sheep during the peri-implantation period of pregnancy.

Polyamines (putrescine, spermidine, and spermine) and agmatine are essential for many cellular functions including proliferation, gene transcription and translation, angiogenesis, and antioxidants for reactive oxygen species [38]. Polyamines are derived from arginine in tissues and fluids of conceptuses during the peri-implantation and throughout the remainder of pregnancy in cattle, sheep, 
and pigs $[34,35]$. Polyamines are essential for mammalian embryogenesis, implantation, and placentation [39-41]. Ovine conceptuses have the greatest amounts of polyamines, arginine, and ornithine on days 15 and 16 of pregnancy, the period of extensive elongation of the conceptus and preparation for adhesion of $\mathrm{Tr}$ cells to uterine LE. This is followed by differentiation of mononuclear trophoblast cells into trophoblast giant cells that will invade the uterine LE to form a syncytial layer [42, 43]. Treatment of ovine $\mathrm{Tr}$ cells with arginine increases their proliferation and production of IFNT through stimulation of the tuberous sclerosis complex 2 (TSC2)-mechanistic target of rapamycin (MTOR) cell signaling pathway [36]. Additionally, knock-down of translation of ornithine decarboxylase $(O D C 1)$ mRNA in ovine conceptuses led to the discovery of a secondary pathway for the conversion of arginine to polyamines via arginine decarboxylase (AZIN2) and agmatinase (AGMAT) enzymes [42]. Later, it was determined that all conceptuses failed to develop when translation of both $O D C 1$ and AZIN2 (reported as ADC by Lenis et al. [44]) mRNAs were knocked down [44].

The present study, as the first in a set of two companion papers, examined specifically the effects of exogenous progesterone on the expression of major genes involved in the arginine-agmatine-polyamine pathway. Additionally, this study extends our previous knowledge on nutrient transport and molecular signaling during the peri-implantation period, and how exogenous P4 treatment affects these mechanisms responsible for advancing morphological development of ovine conceptuses.

\section{Methods}

\section{Animals}

Thirty-eight Suffolk mature ewes (Ovis aries) that had a minimum of two normal estrous cycles were placed with Suffolk rams $(n=5)$ of proven fertility when detected in estrus (day 0 ) for $36 \mathrm{~h}$ and rams were changed every $12 \mathrm{~h}$. All experimental and surgical procedures were in compliance with and approved by Texas A\&M University's Guide for the Care and Use of Agriculture Animals in Research and Teaching.

\section{Experimental design and tissue collection}

Bred ewes $(n=38)$ were assigned randomly to receive daily intramuscular injections of either $25 \mathrm{mg}$ progesterone (P4, $n=18)$ in $1 \mathrm{~mL}$ corn oil vehicle or $1 \mathrm{~mL}$ corn alone $(\mathrm{CO}, n=20)$ from day 1.5 through day 8 of pregnancy. Nine P4-treated ewes and $10 \mathrm{CO}$-treated ewes were euthanized and then hysterectomized on day 9 of pregnancy and 9 P4-treated ewes and 10 CO-treated ewes were euthanized and then hysterectomized on day 12 of pregnancy. Blood samples were taken from ewes via jugular venipuncture immediately prior to euthanasia and hysterectomy. Uterine flushings and blastocysts were collected for analyses by flushing the uterine horn with $10 \mathrm{~mL}$ of sterile phosphate buffered saline into a grid dish $(\mathrm{pH}=7.2)$. The recovered volume of uterine flush was recorded. The volume of uterine flushings recovered for each group was not influenced by day or treatment (day 9 CO: $8.08 \pm 0.08 \mathrm{~mL}$; day 9 P4: $7.99 \pm 0.47 \mathrm{~mL}$; day $12 \mathrm{CO} 8.06 \pm 0.30 \mathrm{~mL}$; and day $12 \mathrm{P} 48.43 \pm 0.06 \mathrm{~mL}$ ). Endometrial tissue from the uterine horn ipsilateral to the CL was collected and snap frozen in liquid nitrogen and stored at $-80^{\circ} \mathrm{C}$ for quantitative real-time polymerase chain reaction (qPCR) analyses. Adjacent tissue was fixed in $4 \%$ paraformaldehyde for $24 \mathrm{~h}$, transferred to $70 \%$ ethanol for $24 \mathrm{~h}$, and then dehydrated through a graded series of alcohol to xylene and embedded in paraffin wax. Photomicroscopic images were taken using a Nikon SMZ18 camera for morphological analyses and volume measurements of all blastocysts and conceptuses in the grid dishes. Uterine flushes were centrifuged $\left(5000 \times g\right.$ for $15 \mathrm{~min}$ at $4{ }^{\circ} \mathrm{C}$ ) aliquoted into $1.5 \mathrm{~mL}$ tubes, and stored at $-20^{\circ} \mathrm{C}$ until analyzed. Blood from ewes was stored on ice and centrifuged $(10,000 \times g$ for $7 \mathrm{~min})$ to obtain plasma for radioimmunoassay. Plasma was aliquoted into $1.5 \mathrm{~mL}$ tubes and stored at $-20^{\circ} \mathrm{C}$ until analyzed.

\section{Radioimmunoassay analysis for concentrations of progesterone in plasma}

Concentrations of $\mathrm{P} 4$ in plasma were determined by using a Progesterone Coated Tube Radioimmunoassay Kit (07-270,102, MP Diagnostics) according to the manufacturer's instructions and as previously described [45]. This radioimmunoassay was validated with $\mathrm{P} 4$ in ovine plasma.

\section{RNA isolation and quantitative real-time PCR analyses}

Total RNA was isolated from endometria from the ipsilateral uterine horn of pregnant ewes with respect to CL using Trizol (Invitrogen) according to manufacturer's instructions. Total RNA samples were cleaned using an RNeasy Mini Kit (Qiagen). RNA was quantified with a NanoDrop (ND-1000 Spectrophotometer) and quality was determined by spectrometry and bioanalysis (Bioanalyzer, Agilent). Samples with a RIN (RNA integrity number) greater than 7 were utilized to synthesize cDNA. Synthesis of cDNA from $5 \mu \mathrm{g}$ total RNA was performed using the SuperScript ${ }^{\mathrm{Tm}}$ First-Strand Synthesis System for qPCR (Invitrogen). Samples without reverse transcriptase were used as negative controls. Gene expression was analyzed via ABI PRISM 7700 (Applied Biosystems) with detector SYBR Green PCR Master Mix (Applied Biosystems) as described previously [26]. All primers (Supplemental Table 1) were designed utilizing NCBI Primer-Blast software. Efficiency of specificity of primers were determined via a standard curve created 
from pooled cDNA in addition to a dissociation curve for qPCR. Standards included serial dilutions of pooled cDNA in RNAse free water (Qiagen) from 1:2 to 1:256 dilution factor. Primers utilized produced a dissociation curve with one peak, signifying one single product. All chosen primers had an efficiency between $95 \%$ and $105 \%$. For all primers excluding AZIN2 and AGMAT, qPCR reactions were performed as described previously [42]. For primers of interest with lower expression (i.e. Cq values above 30; AZIN2 and AGMAT), $1 \mu \mathrm{L}$ of cDNA was used in a modified pre-amplification step [46] using a Thermocycler (Eppendorf AG). Briefly, cDNA, nuclease-free water, forward and reverse primer, and SYBR were combined in a $10-\mu \mathrm{L}$ volume. The reaction was performed with the following conditions for 15 cycles: $94^{\circ} \mathrm{C}$ for $30 \mathrm{~s}$, $58^{\circ} \mathrm{C}$ for $30 \mathrm{~s}$, and $72^{\circ} \mathrm{C}$ for $30 \mathrm{~s}$. Tubulin was used as a reference gene as endometrial expression of tubulin was not affected by day or treatment. All mRNAs were calculated via the comparative Ct method [26].

\section{Immunohistochemistry}

Paraffin-embedded sections $(7 \mu \mathrm{m})$ were subjected to immunohistochemistry to determine cell-specific localization of ODC1, AZIN2, AGMAT, and PGR in endometria. Tissue processing and sectioning were completed as described previously [47]. Antigen retrieval was performed using boiling citrate for ODC1, AGMAT, and PGR and protease $(0.5 \mathrm{mg} / \mathrm{mL}$ in phosphate buffered saline, PBS) for AZIN2. ODC1 protein was detected using a primary rabbit polyclonal antibody to ODC1 (Abcam, ab97395; Cambridge, UK) at a final dilution of 1:500. AZIN2 protein was detected using a primary rabbit polyclonal antibody (Abcam ab192771; Cambridge, UK) at a final dilution of 1:500. AGMAT protein was detected using a primary rabbit polyclonal antibody to AGMAT (Abcam 231,894; Cambridge, UK) at a final dilution of 1 : 250. Primary antibodies, excluding PGR, were replaced with rabbit IgG - Isotype at an equivalent protein concentration (Abcam; ab37355, Cambridge, UK) as a control. PGR protein was detected using a primary mouse monoclonal antibody against human PGR (Invitrogen; MA1-411, Carlsbad, CA, USA) at a final concentration of 1:500. PGR antibody was replaced with mouse IgG Isotype at an equivalent protein concentration (Abcam, ab37355; Cambridge, UK). A universal rabbit and mouse Vectastain kit (Fisher Sci) was used for all proteins visualized in accordance with manufacturer instructions. Chromagen 3,3'-diaminobenzidine tetra-hydrochloride (Sigma) was utilized as the color substrate. Sections were counterstained with Harris hematoxylin (Sigma), dehydrated, and mounted with Permount (Fisher Sci). Imaging of slides was performed with a Nikon Eclipse Ni-U Microscope and NIS-Elements Software (Nikon) at 10x objective.

\section{Image analysis}

All image analyses were performed using ImageJ. Stromal regions containing uterine glands and the luminal epithelial regions of the endometrium were analyzed separately. For analysis of endometrial sections stained for AGMAT and PGR, five non-overlapping images of stromal tissue containing uterine glands were taken at $10 \times$ magnification from each section. The images were split into red, green, and blue channels, and the percentage staining was quantified using the green channel at a threshold of 145- and 105-pixel intensity for AGMAT and PGR stained images respectively. For analysis of LE staining, three nonoverlapping images were taken at $10 \times$ magnification of AGMAT, ODC, AZIN2, and PGR stained endometria from each section. The images were split into red, green, and blue channels and, using the freehand drawing tool on the green channel, the luminal epithelial area was selected, and the percentage staining was quantified [Threshold 145 (AGMAT) or 105 (ODC, AZIN2, and PGR) pixel intensity].

\section{Spectrophotometric assay}

Glucose (Cell Biolabs Inc.) and fructose assay kits (Bioassay Systems, Enzychrom Fructose Assay Kit) were used to determine concentrations of glucose and fructose $(\mathrm{nmol} / \mathrm{mL})$, respectively in uterine flushings. The same glucose assay was used to determine the concentration of glucose in maternal plasma. Only uterine flushings and plasma from ewes which were considered pregnant with normally developed conceptuses were utilized for these analyses. Uterine flushings were diluted 1:2 for glucose and analyzed without dilution for the fructose assay. Maternal plasma was diluted 1:80 for quantification of glucose. Total recoverable glucose and fructose in uterine flushings was calculated by multiplying volume $(\mathrm{mL})$ of uterine flush recovered by the concentration of glucose or fructose $(\mathrm{nmol} / \mathrm{mL})$. Late pregnancy samples from the companion papers to this study that had detectable levels of fructose were used as a positive control for samples in which fructose was undetectable (Halloran et al., unpublished results).

\section{HPLC analyses}

Concentrations of amino acids and polyamines in uterine flushings and maternal plasma were determined via a high-performance liquid chromatography (HPLC) using a method described previously with some modifications [48]. Only uterine flushings and plasma from pregnant ewes were utilized for these analyses. Samples $(100 \mu \mathrm{L})$ were acidified with $100 \mu \mathrm{Lof} 1.5 \mathrm{~mol} / \mathrm{L}^{\mathrm{HClO}} 4$ and deproteinized with $50 \mu \mathrm{L} 2 \mathrm{~mol} / \mathrm{L} \mathrm{K}_{2} \mathrm{CO}_{3}$. The supernatant was diluted 1:10 and subjected to analysis by a precolumn derivatization $o$-phthaldialdehyde (OPA) reagent I or II HPLC method. For analysis of polyamines and agmatine, OPA reagent I was prepared by combining the 
following: $50 \mathrm{mg} \mathrm{N}$-acetyl-cysteine (Sigma-Aldrich) 50 $\mathrm{mg}$ of OPA (Sigma-Aldrich) in $1.25 \mathrm{~mL}$ of HPLC-grade methanol (Fisher Scientific), $11.2 \mathrm{~mL} 0.04 \mathrm{~mol} / \mathrm{L}$ sodium borate (pH 9.5), and $0.5 \mathrm{~mL}$ of Brij-23 (Sigma-Aldrich). For analysis of amino acids, OPA reagent II was prepared by combining the following: $50 \mathrm{mg}$ OPA in 1.25 $\mathrm{mL}$ HPLC-grade methanol, $11.2 \mathrm{~mL}$ sodium borate $(\mathrm{pH}$ 9.5), $50 \mu \mathrm{L}$ 2-mercaptoethanol, and $0.5 \mathrm{~mL}$ of Brij-23 (Sigma-Aldrich). The assay mixture consisted of $100 \mu \mathrm{L}$ of sample, $1.4 \mathrm{~mL}$ of HPLC-grade water (Fisher Scientific), and $100 \mu \mathrm{L}$ of $1.2 \%$ benzoic acid (in $40 \mathrm{mmol} / \mathrm{L}$ sodium borate, $\mathrm{pH}$ 9.5). The assay mixture was derivatized in an autosampler (model 712 WISP, Waters) using 30 $\mathrm{mmol} / \mathrm{L}$ OPA reagent 1 or II before $15 \mu \mathrm{L}$ of the derivatized mixture was injected into a Supelco $3-\mu \mathrm{m}$ reversed-phase C18 column $(150 \mathrm{~mm} \times 4.6 \mathrm{~mm}$ inner diameter, Sigma-Aldrich). Separation of amino acids, polyamines, and agmatine occurred using a solvent gradient consisting of solution A $(0.1 \mathrm{~mol} / \mathrm{L}$ sodium acetate, $18 \%$ methanol, and $1 \%$ tetrahydrofuran, $\mathrm{pH} 7.2$ ) and solution B (methanol). All samples were quantified relative to authentic standards with Millenium-32 Software (Waters). Total amounts of amino acids, polyamines, and agmatine in maternal plasma and uterine flush were calculated by multiplying concentration by fluid volume.

\section{Statistical analysis}

Data from the radioimmunoassay were analyzed via twoway analysis of variance (ANOVA) with ewe, treatment, and day as main effects and day by treatment as the interaction. Relative expression of mRNAs from qPCR analyses were analyzed using Proc GLM in SAS with data expressed as least square means (LSM) with standard errors of means (SEM) [49]. The probability of survival of blastocysts was determined by using the GLIM MX procedure in SAS with a maximum likelihood estimation technique. Data are represented as LSM \pm SEM, with significant differences denoted by a different superscript letter. Statistical significance was set at $P<0.05$ ) and trends for significance set at $(P<0.1)$.

\section{Results}

\section{Concentrations of progesterone (P4) in maternal plasma}

A day $\times$ treatment interaction was identified for concentrations of $\mathrm{P} 4$ in maternal plasma $(P<0.05)$. Concentrations of $\mathrm{P} 4$ were greater in plasma of $\mathrm{P} 4$-treated than CO-treated ewes on day 9 of pregnancy, but on day 12 there was no difference in concentrations of P4 in plasma between P4- and CO-treated ewes (Fig.1a).

\section{Effects of exogenous P4 on blastocyst morphology, volume, and survival}

Blastocysts from P4-treated ewes $\left(0.025 \mathrm{~mm}^{3} \pm 0.015\right.$ $\mathrm{mm}^{3}$ ) had, on average, greater volumes than blastocysts $\left(0.013 \mathrm{~mm}^{3} \pm 0.004 \mathrm{~mm}^{3}\right)$ from control ewes on day 9, but differences in volumes were not statistically significant, presumably due to low sample size and natural variation. All conceptuses recovered from P4-treated ewes on day 12 were elongated and filamentous while conceptuses from CO-treated ewes were spherical (Fig. 1b). Ewes from which malformed blastocysts or unfertilized oocytes were recovered were considered not pregnant. Embryos which were arrested at the morula stage or that had ill-defined ICM and Tr based on quality standards described by the International Embryo Technology Society were considered malformed and not included in the study.

From the total 38 ewes bred, 6 day 9 P4-treated, 5 day 9 CO-treated, 4 day 12 P4-treated, and 9 day 12 COtreated ewes were considered pregnant at the time of necropsy. A Maximum Likelihood test was performed using SAS to compare the number of blastocysts recovered with the number of CL present on the ovaries at necropsy (Fig. 1c). Blastocysts from day $12 \mathrm{CO}$-treated ewes had a greater chance of surviving than those from day 12 P4-treated ewes $(P<0.05)$. There were no differences in the probability for survival of blastocysts from day 9 P4-treated and day 9 CO-treated ewes $(P>0.05)$. There was a day $\times$ treatment interaction $(P<0.05)$.

\section{Effects of exogenous P4 on total glucose in uterine flushings}

Total glucose in uterine flushings was affected by day $(P<0.01)$, and day $\times$ treatment interaction $(P<0.05)$ (Fig. 1d,e). Ewes necropsied on day 12 of pregnancy had greater concentrations of glucose in uterine flushings than ewes necropsied on day 9 of pregnancy $(P<0.01)$. $\mathrm{P} 4$ and CO-treated ewes necropsied on day 12 of pregnancy had greater concentrations of glucose in uterine flushings than $\mathrm{CO}$-treated ewes necropsied on day 9 of pregnancy $(P<0.05)$. Glucose concentrations in maternal plasma were affected by treatment but not day or their interaction (Fig. 1f,g). There was a trend for greater concentrations of glucose in the plasma of P4-treated ewes $(P<0.1)$. Fructose was not detectable in uterine flushings from either day 9 or day 12 of pregnancy.

\section{Amino acids in maternal plasma and uterine flushings}

Concentrations of amino acids in maternal plasma and uterine flushings are summarized in Tables 1 and 2, respectively. The most abundant amino acids in maternal plasma were glutamate, glycine, citrulline, arginine, alanine, valine, and leucine. There was a day $\times$ treatment interaction $(P<0.05)$ for aspartate in maternal plasma and concentrations of aspartate were greater in the plasma of P4-treated than CO-treated ewes on day 12. Concentrations of citrulline $(P<0.1)$ tended to be greater in the plasma of P4-treated than CO-treated ewes. Concentrations of aspartate were greater in the 


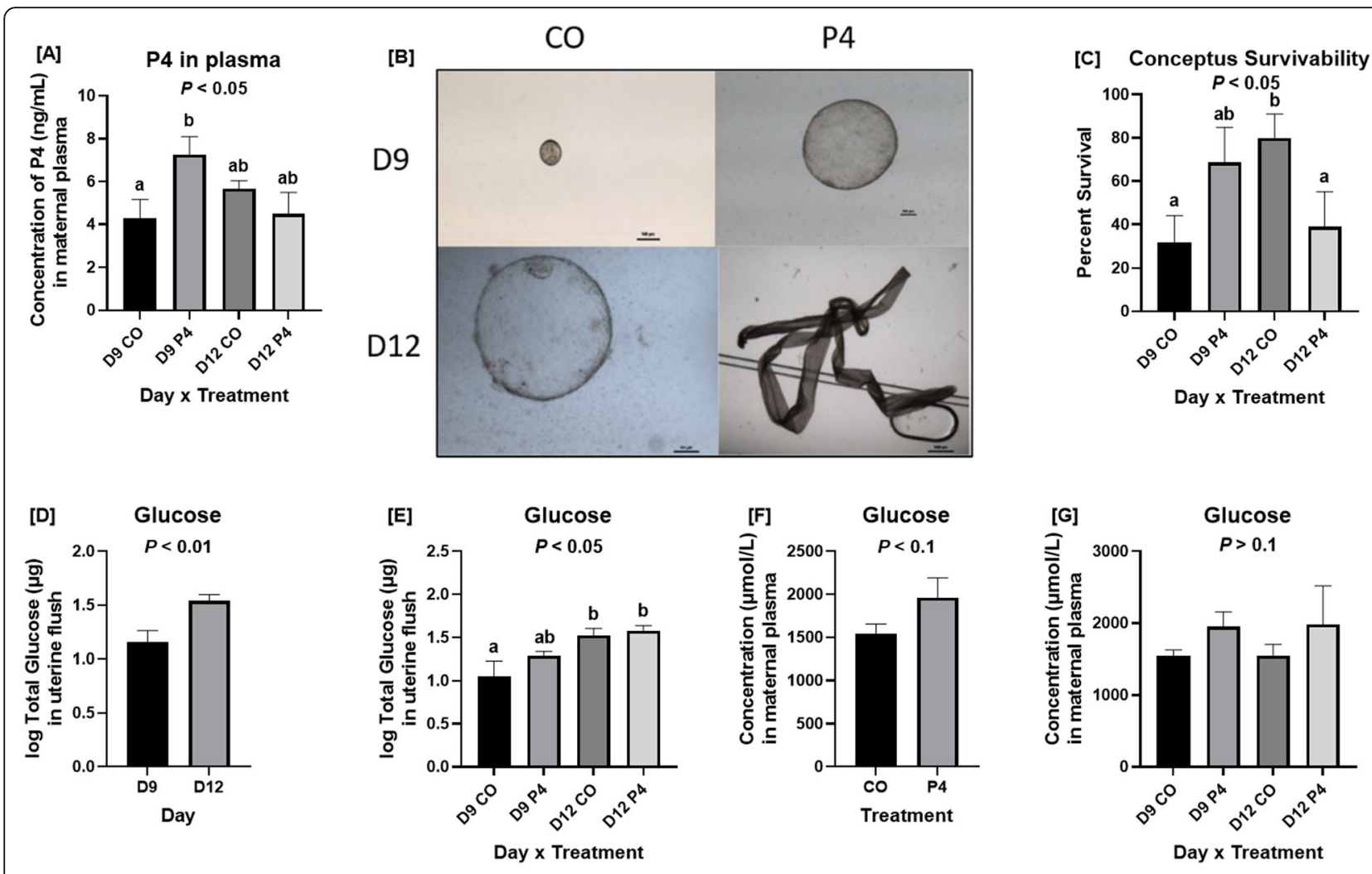

Fig. 1 Effects of exogenous progesterone on blastocyst morphology, and plasma and uterine flushing composition. a Ewes necropsied on day 9 of pregnancy and treated with P4 had higher concentrations of P4 in plasma than CO-treated ewes $(P<0.05)$ but on day 12 concentrations of P4 in plasma were not different. There was a day $\times$ treatment interaction $(P<0.05)$. b All conceptuses from day 12 P4-treated ewes were filamentous while blastocysts from day 12 CO-treated ewes were spherical. The scale bar represents $100 \mu \mathrm{m}$ for spherical blastocysts and $1000 \mu \mathrm{m}$ for filamentous conceptuses. c Blastocysts from day 12 CO-treated ewes had a greater chance of surviving than those from day 12 P4-treated ewes $(P<0.05)$. There were no differences in the probability for survival of blastocysts from day 9 P4-treated and day 9 CO-treated ewes. There was a day $\times$ treatment interaction $(P<0.05)$. $\mathbf{d}$ Ewes necropsied on day 12 of pregnancy had greater concentrations of glucose in uterine flushings than ewes necropsied on day 9 of pregnancy $(P<0.01)$. e P4 and CO-treated ewes necropsied on day 12 of pregnancy had greater concentrations of glucose in uterine flushings than CO-treated ewes necropsied on day 9 of pregnancy $(P<0.05)$. $\mathbf{f}$ There was a trend for greater concentrations of glucose in the plasma of P4-treated ewes $(P<0.1)$. $\mathbf{g}$ Glucose concentrations in maternal plasma were affected by treatment but not day or their interaction. Data are presented as LSM \pm SEM. Different means are indicated by different letters. Only uterine flushings and plasma from ewes which were considered pregnant with normally developed conceptuse were utilized for these analyses

plasma of ewes on day 9 compared to day 12 of gestation $(P<0.05)$. In contrast, concentrations of $\beta$-alanine were greater in the plasma of ewes on day 12 than day 9 of gestation $(P<0.05)$.

Glutamate, serine, glycine, and taurine were the most abundant amino acids in uterine flushings. A day $\times$ treatment interaction was observed for concentrations of aspartate $(P<0.05)$, glutamate $(P<0.01)$, asparagine $(P<$ $0.05)$, serine $(P<0.05)$, and isoleucine $(P<0.05)$. Concentrations of aspartate $(P<0.001)$, glutamate $(P<0.01)$, asparagine $(P<0.01)$, glutamine $(P<0.01)$, threonine $(P<$ $0.05)$, alanine $(P<0.05)$, and ornithine $(P<0.01)$ were all greater in uterine flushings from ewes on day 12 than day 9 of pregnancy. Concentrations of serine, histidine, arginine, methionine, and leucine all tended to be greater in uterine flushings from ewes on day 12 than day 9 of pregnancy $(P<0.1)$. Concentrations of glutamate were less in the uterine flushings of P4-treated ewes on day 9 of pregnancy than CO-treated and P4-treated ewes on day 12 of pregnancy $(P<0.01)$. Concentrations of serine in uterine flushings were greater in P4-treated ewes on day 9 and 12 of pregnancy and CO-treated ewes necropsied on day 12 of pregnancy than in CO-treated ewes necropsied on day 9 of pregnancy $(P<0.05)$. Concentrations of isoleucine were greater in uterine flushings from $\mathrm{P} 4$-treated ewes than for CO-treated ewes on day 12 of gestation $(P<$ $0.05)$. Serine was more abundant in uterine flushings from P4-treated than CO-treated ewes necropsied on day 9 of pregnancy $(P<0.05)$.

\section{Agmatine and polyamines in maternal plasma and uterine flushings}

Overall, agmatine was more abundant than any of the polyamines in maternal plasma $(P<0.001)$ (Fig. $2 a)$. In 
Table 1 Concentrations of amino acids, agmatine, and polyamines in maternal plasma $(\mathrm{nmol} / \mathrm{mL})$

\begin{tabular}{|c|c|c|c|c|}
\hline \multirow[b]{3}{*}{ Nutrient } & \multicolumn{4}{|l|}{ Effect } \\
\hline & \multicolumn{2}{|l|}{ Day 9} & \multicolumn{2}{|l|}{ Day 12} \\
\hline & $\mathrm{CO}$ & P4 & $\mathrm{CO}$ & P4 \\
\hline \multicolumn{5}{|l|}{ Amino Acid } \\
\hline Alanine & $208.8 \pm 26$ & $170.7 \pm 15.8$ & $179.5 \pm 12.9$ & $207.4 \pm 14.4$ \\
\hline$\beta$-Alanine & $7.9 \pm 1.6^{\mathrm{a}}$ & $7.9 \pm 1^{\mathrm{a}}$ & $10.5 \pm 1.1^{b}$ & $9.9 \pm 0.6^{b}$ \\
\hline Arginine & $229.4 \pm 32.1$ & $168.5 \pm 16.6$ & $202.3 \pm 13.5$ & $206.1 \pm 7.1$ \\
\hline Asparagine & $21.5 \pm 4.5$ & $23.2 \pm 4.5$ & $21.1 \pm 3.1$ & $19.9 \pm 2.2$ \\
\hline Aspartate & $1.5 \pm 0.4^{\mathrm{ab}}$ & $2.6 \pm 0.3^{a}$ & $0.8 \pm 0.2^{b}$ & $1.6 \pm 0.7^{\mathrm{ab}}$ \\
\hline Citrulline & $172.3 \pm 20.4$ & $198.2 \pm 23$ & $171.9 \pm 28.6$ & $246.8 \pm 26.3$ \\
\hline Glutamate & $240.4 \pm 17.2$ & $236.5 \pm 14.6$ & $219.7 \pm 14.2$ & $226.6 \pm 21.6$ \\
\hline Glutamine & $17.6 \pm 5.2$ & $21.5 \pm 7.1$ & $24.9 \pm 3.9$ & $32.5 \pm 4.6$ \\
\hline Glycine & $384.6 \pm 47.6$ & $333 \pm 65$ & $322.9 \pm 24.1$ & $242.1 \pm 22.5$ \\
\hline Histidine & $28.4 \pm 3.5$ & $28 \pm 5$ & $28.9 \pm 2.8$ & $32.4 \pm 1.8$ \\
\hline Isoleucine & $82.9 \pm 10.7$ & $65.8 \pm 4.3$ & $66.3 \pm 5$ & $70.2 \pm 7.9$ \\
\hline Leucine & $164.9 \pm 26.3$ & $164.3 \pm 18.9$ & $138.2 \pm 13.7$ & $164.1 \pm 16.2$ \\
\hline Lysine & $115.5 \pm 25.4$ & $79 \pm 7.1$ & $91.1 \pm 11.6$ & $96.8 \pm 18.2$ \\
\hline Methionine & $27.1 \pm 5.5$ & $24.8 \pm 3$ & $24.9 \pm 2.8$ & $23.1 \pm 2.1$ \\
\hline Ornithine & $99.5 \pm 33.3$ & $102.4 \pm 20.3$ & $83.5 \pm 12.7$ & $119.2 \pm 33.6$ \\
\hline Phenylalanine & $51.1 \pm 5.8$ & $54.7 \pm 4.9$ & $46.2 \pm 6.2$ & $48.6 \pm 2.3$ \\
\hline Serine & $70 \pm 8.3$ & $53.3 \pm 14.4$ & $54.6 \pm 7.5$ & $51.7 \pm 5.1$ \\
\hline Taurine & $78.5 \pm 23.1$ & $86.8 \pm 17$ & $68.7 \pm 12.2$ & $72.8 \pm 7.6$ \\
\hline Threonine & $95.3 \pm 20.9$ & $110.8 \pm 29.2$ & $89.7 \pm 16.1$ & $92.1 \pm 10.4$ \\
\hline Tryptophan & $41.6 \pm 6.8$ & $43.6 \pm 2.1$ & $41.6 \pm 4.3$ & $43.8 \pm 2.2$ \\
\hline Tyrosine & $66.2 \pm 8.6$ & $69.5 \pm 5.6$ & $64.1 \pm 4.9$ & $69 \pm 8.7$ \\
\hline Valine & $198.7 \pm 30.3$ & $224.8 \pm 18.7$ & $185.7 \pm 19.3$ & $215.1 \pm 23.3$ \\
\hline \multicolumn{5}{|c|}{ Agmatine and polyamines } \\
\hline Agmatine & $54.2 \pm 9.6$ & $53.6 \pm 5.8$ & $57.6 \pm 2.9$ & $57.54 \pm 3.5$ \\
\hline Putrescine & $1.5 \pm 0.4$ & $1.1 \pm 0.2$ & $1.3 \pm 0.1$ & $1.3 \pm 0.3$ \\
\hline Spermidine & $2.5 \pm 0.1^{\mathrm{ab}}$ & $2.9 \pm 0.2^{a}$ & $2.3 \pm 0.1^{b}$ & $2.5 \pm 0.1^{\mathrm{ab}}$ \\
\hline Spermine & $4.4 \pm 0.4^{a}$ & $6.2 \pm 0.7^{\mathrm{a}}$ & $2.7 \pm 0.1^{b}$ & $3.3 \pm 0.1^{b c}$ \\
\hline
\end{tabular}

Values represent means \pm SEM

Different superscripts within Effect columns are significantly different $(P<0.05)$ Only maternal plasma from ewes which were considered pregnant with normally developed conceptuse were utilized for these analyses

maternal plasma, concentrations of spermidine $(P<0.05)$ and spermine $(P<0.001)$ were affected by a day $\times$ treatment interaction (Fig. 2c,d). Concentrations of spermidine and spermine were greater for P4-treated compared to CO-treated ewes $(P<0.05)$ (Fig. 2f,h) while concentrations of spermidine $(P<0.05)$ and spermine $(P<0.001)$ were greater on day 9 than day 12 of pregnancy (Fig. 2g,i).

Interestingly, agmatine was less abundant than all other polyamines in uterine flushings from ewes in all treatment groups (Fig. 3a). Concentrations of agmatine in uterine flushings were less in those from P4-treated than CO-treated ewes $(P<0.01)$ and concentrations of spermidine tended to be less in the uterine flushings from P4-treated than CO-treated ewes $(P<0.1)$ (Fig. 3f, g). There was no effect of day of pregnancy on abundances of agmatine or polyamines in uterine flushings (Fig. 3b,c,d,e).

\section{Expression of mRNAs in the endometrium}

Expression of $S L C 2 A 1$ (facilitated glucose transporter) mRNA was greater $(P<0.001)$ in the endometria of ewes on day 12 of pregnancy, and there was a day $\times$ treatment interaction $(P<0.001)$, but no effect of treatment was observed (Fig. 4i,n). Expression of SLC5A1 mRNA (glucose and sodium co-transporter) was greater on day 12 than day 9 of pregnancy $(P<0.001)$ and expression was affected by a day $\times$ treatment interaction $(P<0.001)$, but not treatment (Fig. 4j,o). Similarly, expression of SLC7A1 mRNA (cationic amino acid transporter) was affected by day $(P<0.001)$ and a day $\times$ treatment interaction $(P<0.001)$, but not treatment (Fig. $4 \mathrm{k}, \mathrm{p})$. Ewes on day 12 of pregnancy had greater expression of endometrial SLC7A1 mRNA than ewes necropsied on day 9 of pregnancy.

There was no treatment, day, or day $\times$ treatment interaction for expression of FGF7 mRNA in endometria (Fig. 4a). However, expression of FGF10 was affected by treatment $(P<0.05)$ and a day $\times$ treatment interaction $(P<0.01)$, but not day (Fig. 4b,d). CO-treated ewes on day 12 of pregnancy and P4-treated ewes on day 9 and day 12 of pregnancy had greater $(P<0.05)$ expression of FGF10 mRNA in their endometria than CO-treated ewes on day 9 of pregnancy. P4-treated ewes had greater $(P<$ 0.05) expression of FGF10 mRNA in their endometria than CO-treated ewes. Expression of HGF in endometria was not affected by treatment, day or their interaction (Fig. 4c).

SLC6A9 mRNA (sodium- and chloride-dependent glycine transporter 1) endometrial expression was affected by treatment $(P<0.05)$ and day $\times$ treatment interaction $(P<0.05)$ but not day (Fig. 4l,q). Expression of SLC1A4 mRNA (neutral amino acid transporter for amino acids including serine) in endometria was affected by treatment $(P<0.05)$ and a day $\times$ treatment interaction $(P=$ 0.053), but not day of pregnancy (Fig. $4 \mathrm{~m}, \mathrm{r}$ ). Endometria from P4-treated ewes on d 12 of gestation expressed less SLC1A4 than CO-treated ewes on days 9 and 12 of gestation and P4-treated ewes on day 9 of gestation $(P=$ 0.053). Overall, CO-treated ewes had greater $(P<0.05)$ expression of both SLC6A9 and SLC1A4 than P4-treated ewes.

Endometrial expression of $O D C 1$ mRNA was affected by a day $\times$ treatment interaction $(P<0.05)$, but not day of gestation or treatment (Fig. 4e). CO-treated ewes on day 9 of pregnancy had greater expression of $O D C 1$ 
Table 2 Total amino acids, agmatine, and polyamines in uterine flushings $(\mu \mathrm{g})$

\begin{tabular}{|c|c|c|c|c|}
\hline \multirow[b]{3}{*}{ Nutrient } & \multicolumn{4}{|l|}{ Effect } \\
\hline & \multicolumn{2}{|l|}{ Day 9} & \multicolumn{2}{|l|}{ Day 12} \\
\hline & $\mathrm{CO}$ & P4 & $\mathrm{CO}$ & P4 \\
\hline \multicolumn{5}{|l|}{ Amino Acid } \\
\hline Alanine & $5 \pm 1.5^{\mathrm{a}}$ & $7.2 \pm 1.9^{\mathrm{a}}$ & $8.6 \pm 2.2^{a}$ & $17.8 \pm 1.4^{b}$ \\
\hline$\beta$-Alanine & $0.2 \pm 0.04$ & $0.4 \pm 0.2$ & $0.4 \pm 0.1$ & $0.5 \pm 0.2$ \\
\hline Arginine & $2.5 \pm 1.3$ & $4.1 \pm 1.8$ & $7.2 \pm 2.2$ & $8.3 \pm 3.8$ \\
\hline Asparagine & $1.5 \pm 0.5^{\mathrm{a}}$ & $1.8 \pm 0.6^{\mathrm{ab}}$ & $4.2 \pm 1^{\mathrm{ab}}$ & $5.2 \pm 0.6^{b}$ \\
\hline Aspartate & $2.2 \pm 0.5^{\mathrm{ab}}$ & $1.6 \pm 0.3^{\mathrm{a}}$ & $4.1 \pm 0.8^{b}$ & $4.2 \pm 0.5^{\mathrm{ab}}$ \\
\hline Citrulline & $0.7 \pm 0.2$ & $3.4 \pm 1.6$ & $3.7 \pm 1.1$ & $1.8 \pm 1.2$ \\
\hline Glutamate & $17.5 \pm 3.6^{\mathrm{ab}}$ & $8.8 \pm 1.3^{\mathrm{a}}$ & $23.8 \pm 3.5^{b}$ & $29.1 \pm 3.5^{b}$ \\
\hline Glutamine & $3.1 \pm 1$ & $3.7 \pm 1.5$ & $11.5 \pm 2.7$ & $12.1 \pm 2.3$ \\
\hline Glycine & $65.6 \pm 21.4$ & $81.5 \pm 16.4$ & $76.6 \pm 14.8$ & $59 \pm 4.8$ \\
\hline Histidine & $0.8 \pm 0.4$ & $1.4 \pm 0.6$ & $2.1 \pm 0.5$ & $2.4 \pm 0.9$ \\
\hline Isoleucine & $2 \pm 1.8^{\mathrm{ab}}$ & $1.5 \pm 0.2^{a}$ & $1.5 \pm 0.2^{\mathrm{a}}$ & $3.1 \pm 0.4^{b}$ \\
\hline Leucine & $6 \pm 1.8$ & $3.7 \pm 1.1$ & $6.6 \pm 1.2$ & $9.1 \pm 1.2$ \\
\hline Lysine & $6 \pm 2$ & $2.8 \pm 0.6$ & $5.2 \pm 1.5$ & $10.9 \pm 2.7$ \\
\hline Methionine & $1.4 \pm 0.6$ & $1.1 \pm 0.5$ & $2 \pm 0.6$ & $3.4 \pm 1$ \\
\hline Ornithine & $0.2 \pm 0.06^{\mathrm{a}}$ & $0.4 \pm 0.1^{\mathrm{ab}}$ & $0.5 \pm 0.1^{\mathrm{ab}}$ & $0.9 \pm 0.2^{b}$ \\
\hline Phenylalanine & $2.7 \pm 0.9$ & $1.9 \pm 0.5$ & $1.9 \pm 0.4$ & $3.5 \pm 1$ \\
\hline Serine & $12 \pm 3.6^{\mathrm{a}}$ & $41.1 \pm 12.2^{b}$ & $41.4 \pm 10.1^{b}$ & $52.9 \pm 13.1^{b}$ \\
\hline Taurine & $20 \pm 8.3$ & $18.3 \pm 4.4$ & $23 \pm 5.7$ & $25.5 \pm 0.7$ \\
\hline Threonine & $3.4 \pm 1.4$ & $6.7 \pm 1.7$ & $13.4 \pm 3.8$ & $12.4 \pm 3.9$ \\
\hline Tryptophan & $0.7 \pm 0.4$ & $1.3 \pm 0.4$ & $1.6 \pm 0.3$ & $1.4 \pm 0.7$ \\
\hline Tyrosine & $1.7 \pm 0.8$ & $1.3 \pm 0.4$ & $1.2 \pm 0.2$ & $2.9 \pm 1.3$ \\
\hline Valine & $10 \pm 3.4$ & $5.6 \pm 1.4$ & $6.1 \pm 1.1$ & $5.8 \pm 0.6$ \\
\hline \multicolumn{5}{|c|}{ Agmatine and polyamines } \\
\hline Agmatine & $0.1 \pm 0.04$ & $0.04 \pm 0.01$ & $0.08 \pm 0.02$ & $0.02 \pm 0.0001$ \\
\hline Putrescine & $1.1 \pm 0.5$ & $0.8 \pm 0.4$ & $1.1 \pm 0.3$ & $0.1 \pm 0.03$ \\
\hline Spermidine & $0.9 \pm 0.4$ & $0.8 \pm 0.4$ & $1.3 \pm 0.3$ & $0.1 \pm 0.03$ \\
\hline Spermine & $1.2 \pm 0.6$ & $2 \pm 1.2$ & $2.3 \pm 0.7$ & $1.1 \pm 0.8$ \\
\hline
\end{tabular}

Values represent means \pm SEM

Different superscripts within Effect columns are significantly different $(P<0.05)$

Only uterine flushings from ewes which were considered pregnant with normally developed conceptuses were utilized for these analyses

mRNA than P4-treated ewes on either day 9 or day 12 of pregnancy and CO-treated ewes on day 12 of pregnancy $(P<0.05)$. Endometrial expression of AZIN2 mRNA was affected by treatment $(P<0.05)$, but not by a day or day $\times$ treatment interaction (Fig. 4f,h). Expression of AZIN2 mRNA was less for P4-treated than COtreated ewes. Expression of AGMAT was unaffected by treatment, day, or day $\times$ treatment interaction (Fig. $4 \mathrm{~g}$ ).

\section{Localization of enzymes associated with synthesis of polyamines in endometria}

AZIN2 and ODC1 (Fig. 5) proteins localized to uterine LE, sGE, and stromal cells in both P4- and CO-treated ewes. AZIN2 staining intensity in LE was not altered by day or treatment (Fig. 5a and b). In contrast, a decrease in ODC1 staining intensity was observed in P4-treated ewes compared to CO-treated ewes (Fig. 5c and d). AGMAT protein localized to the uterine LE, sGE, GE, and stromal cells in both P4- and CO-treated ewes (Fig. 6). Decreased intensity of AGMAT staining was observed in the GE of ewes necropsied on day 12 of gestation compared to day 9 (Fig. 6a and b). Interestingly, a day $\times$ treatment interaction was observed for AGMAT staining in the LE, with LE in endometria from P4-treated ewes having increased intensity of AGMAT staining compared to CO-treated ewes necropsied on day 12 of gestation (Fig. 6a and c). 


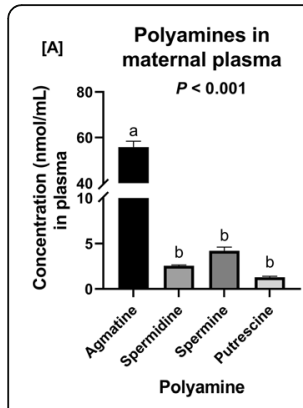

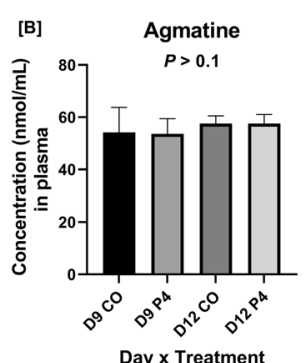

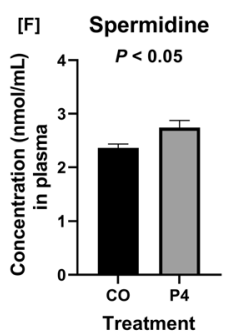

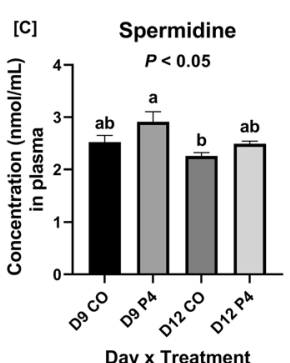

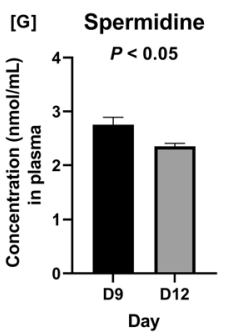

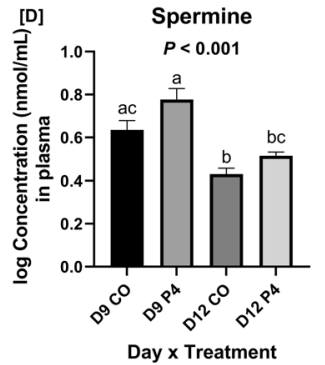

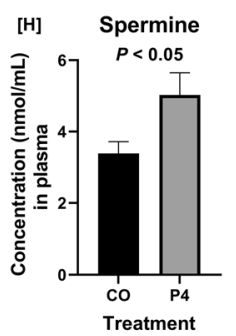

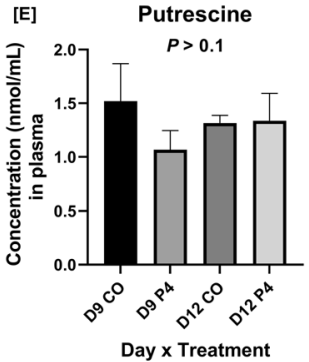

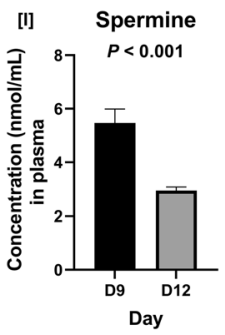

Fig. 2 Concentrations of agmatine and polyamines in maternal plasma. a Agmatine was more abundant than any of the polyamines in maternal plasma $(P<0.001)$. $\mathbf{b}$ There was not a significant day $\times$ treatment interaction for concentrations of agmatine in maternal plasma. $\mathbf{c}$ Concentrations of spermidine in maternal plasma were affected by a day $\times$ treatment interaction $(P<0.05)$. $\mathbf{d}$ Concentrations of spermine in maternal plasma were affected by a day $x$ treatment interaction $(P<0.001)$. e Concentrations of putrescine in maternal plasma were not affected by a day $\times$ treatment interaction. $\mathbf{f} P 4$-treated ewes had lower concentrations of spermidine in maternal plasma than CO-treated ewes $(P<0.05)$. $\mathbf{g}$ Ewes on day 12 of gestation had decreased amounts of spermidine in plasma than ewes on day 9 of gestation. $\mathbf{h}$ P4-treated ewes had greater amounts of spermine in their plasma than CO-treated ewes $(P<$ 0.05). i Ewes on day 12 of pregnancy had decreased amounts of spermine in maternal plasma than ewes on day 9 of pregnancy $(P<0.01)$. Only plasma from ewes which were considered pregnant with normally developed conceptuses were utilized for these analyses

PGR protein was localized to endometrial LE, sGE, and GE, with differences in staining intensity and localization observed depending on treatment and day (Fig. 7). PGR staining was less intense in ewes necropsied on day 12 of gestation compared to day 9 of gestation (Fig. 7b and c). Increased intensity of PGR staining was observed in the GE (Fig. 7a and b) in control ewes compared to P4-treated ewes necropsied on day 9 and 12. Whilst a significant decrease in the intensity of PGR staining in GE was observed in P4treated ewes compared to CO-treated ewes necropsied on day 12 (Fig. 7a), LE expression of PGR had similar localization and intensity between $\mathrm{CO}$ - and P4-treated ewes.

\section{Discussion}

In the present study, exogenous $\mathrm{P} 4$ given to pregnant ewes from days 1.5 to 8 of pregnancy resulted in elongated, filamentous conceptuses while control ewes administered corn oil had spherical blastocysts on day 12 of pregnancy. These results confirm previous findings and clearly demonstrate that an early increase in concentrations of $\mathrm{P} 4$ induce changes in endometrial functions that accelerate development of the conceptus during the peri-implantation stages of development. Of particular interest is the discovery that treatment with P4 and/or day of gestation alters some key metabolic parameters, including amino acids in the maternal plasma, uterine flushings, and the expression of multiple genes in the endometrium. Previous research demonstrated that administration of exogenous P4 during the preimplantation period of pregnancy advances growth and development of bovine and ovine conceptuses [21, 30, 31]. This phenomenon has previously been attributed to the 

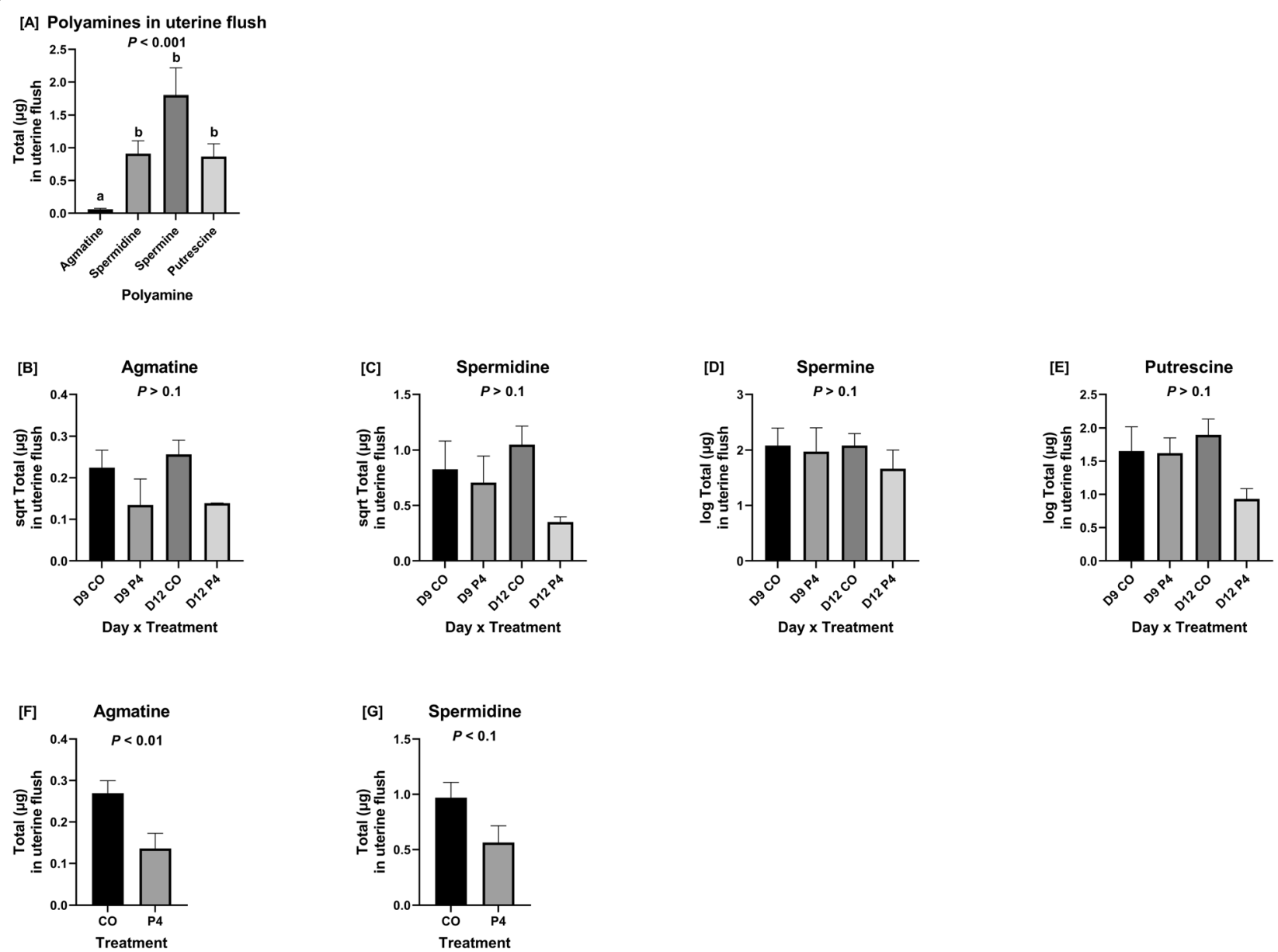

Fig. 3 Concentrations of agmatine and polyamines in uterine flushings. a Agmatine was less abundant than any of the polyamines in uterine flushings. $\mathbf{b}$ Concentrations of agmatine in uterine flushings were not affected by a day $\times$ treatment interaction. $\mathbf{c}$ Concentrations of spermidine in uterine flushings were unaffected by a day $\times$ treatment interaction. $\mathbf{d}$ Concentrations of spermine in uterine flushings were not affected by a day $\times$ treatment interaction. e Concentrations of putrescine in uterine flushings were not affected by a day $\times$ treatment interaction. $\mathbf{f}$ P4-treated ewes had lower concentrations of agmatine in uterine flushings than CO-treated ewes $(P<0.01)$. g P4-treated ewes tended to have lower concentrations of spermidine in uterine flushings than CO-treated ewes $(P<0.1)$. Only uterine flushings from ewes which were considered pregnant with normally developed conceptuses were utilized for these analyses

advancement of the down-regulation of PGR in endometrial sGE and LE [22]. Without exogenous progesterone treatment, PGR is present from day 9 to day 11 [18]. In the present study, immunohistochemical localization of PGR confirmed that advancement of PGR downregulation occurred in the present study. It is important to note that in addition to down-regulation of PGR, the ewes and conceptuses would also be subjected to a decrease in $\mathrm{P} 4$ following cessation of $\mathrm{P} 4$ treatment. Considering this, there may be other indirect effects of $\mathrm{P} 4$ on both the conceptus and the endometrium which warrant further investigation.

This study suggests that blastocysts from day 12 P4treated ewes were less likely to survive than blastocysts from day 12 CO-treated ewes and blastocysts from P4and CO-treated ewes had equivalent rates of survival on day 9 of pregnancy, but results regarding survivability in this study should be considered inconclusive due to low sample size. However, in the companion paper for this study by Halloran et al., it was noted that between breeding and ultrasound pregnancy rates of P4-treated ewes were significantly decreased at $64.7 \%$ compared to the $94 \%$ pregnancy rates of control ewes. In a previous study of ewes treated with either $\mathrm{P} 4$ or $\mathrm{CO}$ and necropsied on day 9 or day 12 of pregnancy, ewes received treatments from day 1.5 through the morning of day 9 or day 12 of pregnancy just prior to necropsy [31]. In the present study, P4 therapy was only administered until day 8 , therefore the initial increase in $\mathrm{P} 4$ concentrations that was observed for P4-treated day 9 ewes was not sustained until day 12. Perhaps, this sudden loss of excess of $\mathrm{P} 4$ is the reason for differences in results for likelihood of survival seen in Halloran et al. and suggested in the present study. In contrast, these findings 


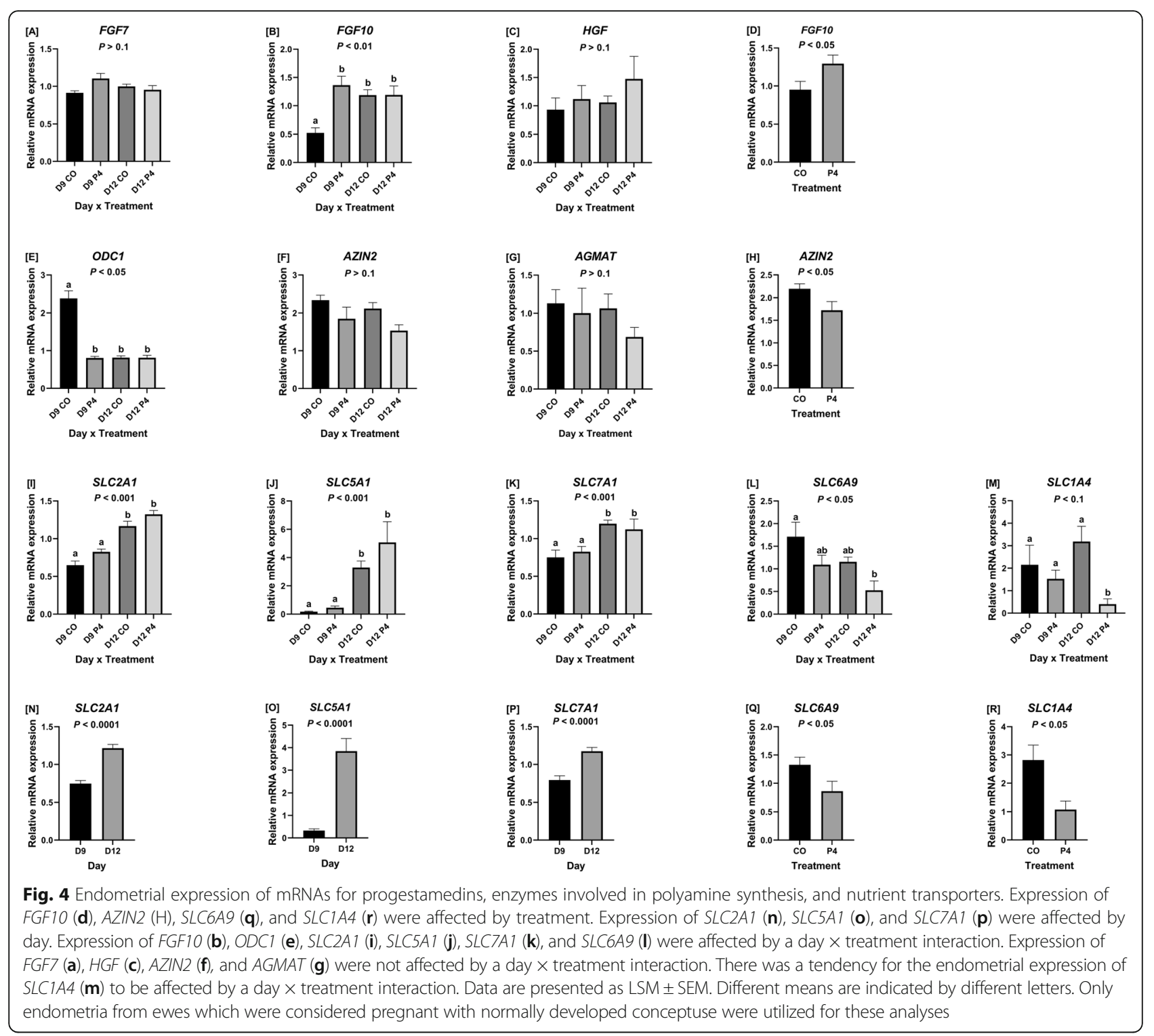

could reflect an adverse effect of P4 treatment to cause an asynchrony between the uterus and conceptus that is known to decrease embryonic survival [50].

Total glucose in uterine flushings increased with advancing day of pregnancy as expected [35] and P4treated ewes tended to have greater concentrations of glucose in maternal plasma. A key advancement in our knowledge beyond that reported by Satterfield et al. [30] for P4 treatment through day 9 of pregnancy is that there was no effect of $\mathrm{P} 4$ treatment on glucose concentrations when pregnancy was extended to day 12 in the present study.

The mRNA expression of two transporters for glucose (SLC2A1 and SLC5A1) and one transporter for arginine (SLC7A1) were examined in the present study as their expression has been shown to increase in the luteal phase of the estrous cycle and equivalent days of gestation [29] and in response to P4 [30, 47]. Endometrial expression of SLC2A1, SLC5A1, and SLC7A1 was affected by day and day $\times$ treatment interaction, but not treatment. Endometrial mRNA expression of both glucose transporters (SLC2A1 and SLC5A1) tended to be greater for P4-treated ewes on day 12 of pregnancy which supports previous findings from our laboratory [30].

The significance of the classical (arginine-ornithineputrescine) and non-classical (arginine-agmatine-putrescine) pathways for synthesis of polyamine is of great interest in our laboratory. The present study is the first to determine whether earlier expression of uterine genes and conceptus development includes increases in expression of ODC1, AZIN2, and SLC7A1. Results of the present study are also the first to indicate that agmatine 


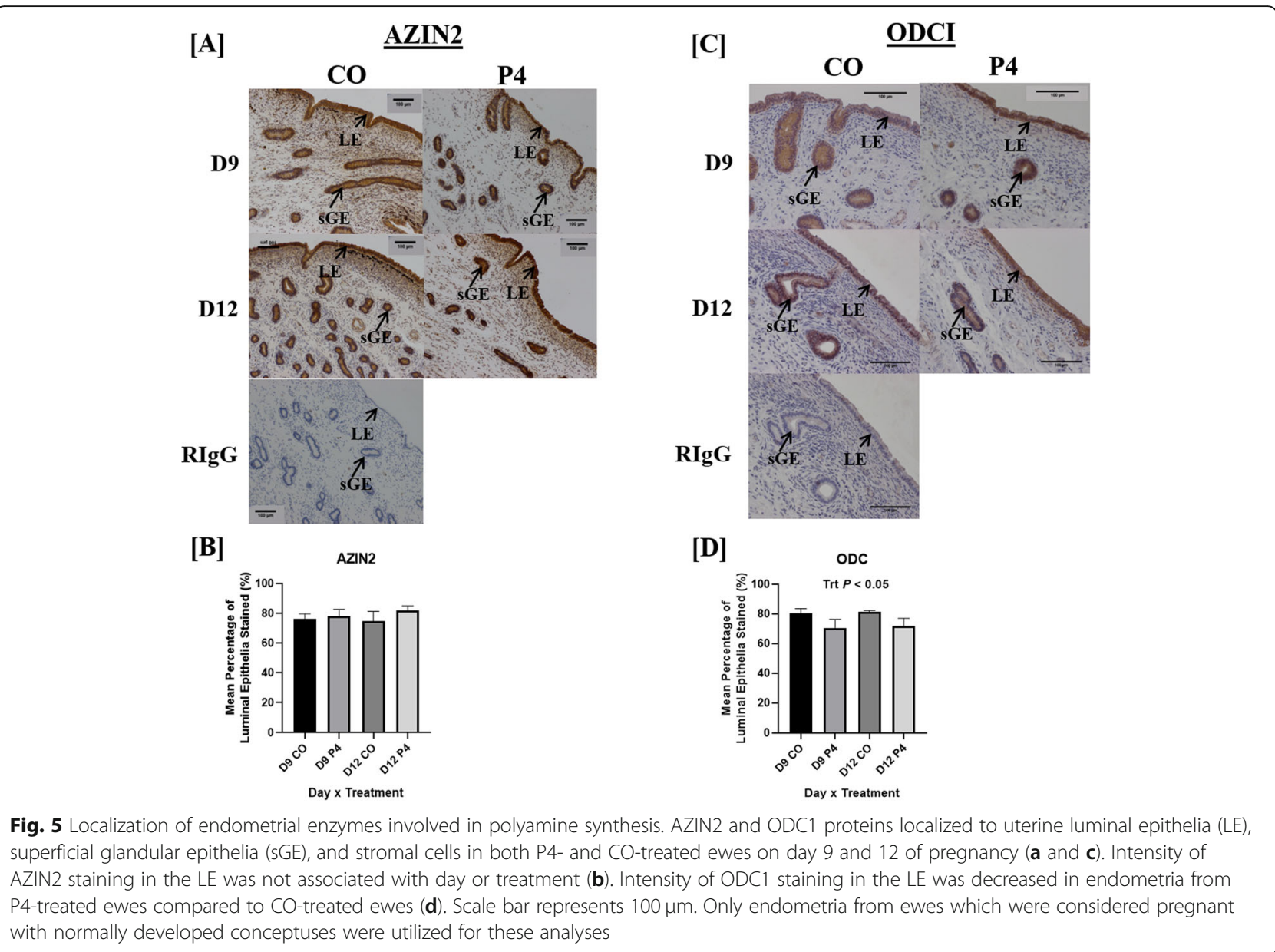

is very abundant in plasma of sheep and in much greater concentrations than those for putrescine, spermidine, taurine and spermine. Thus, agmatine could act as a major substrate for transport from maternal blood to the conceptus for production of polyamines required for growth and development of conceptuses in sheep. Agmatine plays a vital biological role in the synthesis of polyamines required for growth and development of mammalian conceptuses [41]. In ewes, conceptus development fails when translation of mRNAs for both AZIN2 and ODC1 are knocked down since neither arginine nor ornithine can be used for the synthesis of polyamines [44]. In the present study, agmatine was the least abundant polyamine in uterine flushings, but particularly those from P4-treated ewes in which conceptus development was advanced. Perhaps agmatine was used via the novel arginine-agmatine-polyamine pathway to meet demands for polyamines under conditions of accelerated growth and development of the conceptus. Further, concentrations of agmatine may vary depending on whether conceptuses use the classical arginineornithine-polyamine pathway or the arginine-agmatinepolyamine pathway as the primary pathway for synthesis of polyamines. It is also possible that the novel arginineagmatine-polyamine pathway is utilized only when physiological or other conditions, such as nutritional stress, require it to be activated because the classical arginine-ornithine-polyamine pathway is insufficient for the synthesis of required polyamines. It is important to note that concentrations of spermidine tended to be lower in uterine flushings of P4-treated ewes compared to $\mathrm{CO}$-treated ewes as it is the substrate used to produce spermine, perhaps the most bioactive polyamine in the conceptus [51].

Expression of the endometrial cationic amino acid transporter SLC7A1 mRNA increased significantly between days 9 and 12 of pregnancy in the present study, which is consistent with a reported 4-fold increase in SLC7A1 between days 10 and 14 of pregnancy [47] in ewes. Previous studies reported an increase in the basic amino acid transporter $S L C 7 A 2 B$ in endometria of P4treated day 12 ewes, but there was no difference between day 9 CO-treated and day 9 P4-treated ewes [30]. It is unclear why there was no effect of supplemental P4 to increase expression of $S L C 7 A 1$ in the present study, but it could be because $S L C 7 A 1$ requires long-term 


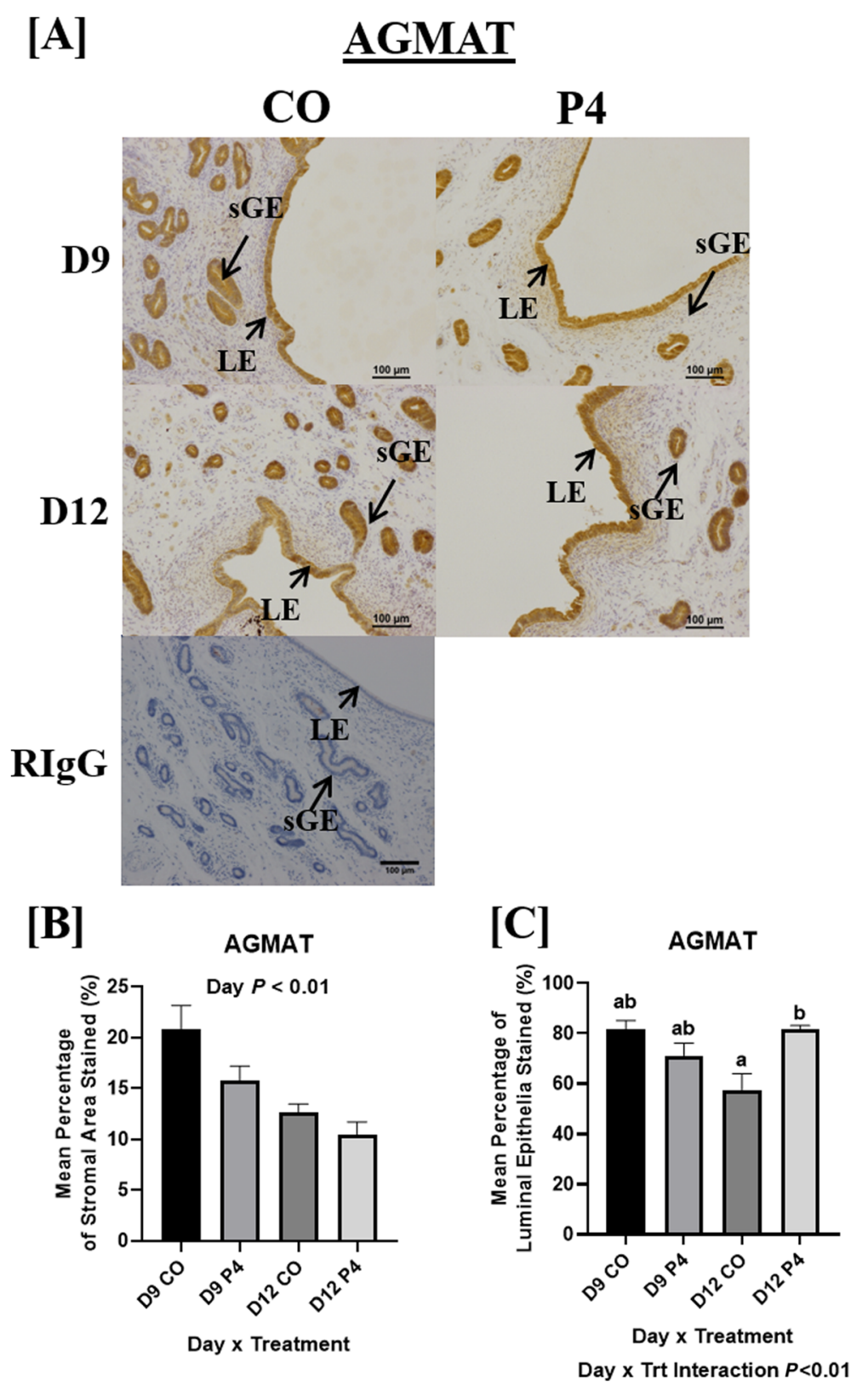

Fig. 6 Localization of endometrial AGMAT. AGMAT proteins localized to uterine luminal epithelia (LE), superficial glandular epithelia (sGE), GE, and stromal cells in both P4- and CO-treated ewes on day 9 and 12 of pregnancy (a). Intensity of AGMAT staining in the GE was decreased in endometria at day 12 compared to day $9(P<0.01)(\mathbf{b})$. A day $\times$ treatment interaction for the intensity of AGMAT staining in the LE was observed $(P<0.001)$, with increased intensity of AGMAT staining observed in the LE from P4-treated ewes compared to CO-treated ewes at day 12 . Scale bar represents $100 \mu \mathrm{m}$. Only endometria from ewes which were considered pregnant with normally developed conceptuses were utilized for these analyses

treatment of P4 (20 days) to induce expression of mRNA in uterine $\mathrm{LE}, \mathrm{GE}$, and stroma while expression of SLC7A2 mRNA increased about 4-fold after short-term $\mathrm{P} 4$ treatment (10 days) and further increased in response to IFNT [47]. Expression of AZIN2 mRNA was less in endometria of P4-treated ewes as were concentrations of agmatine and spermidine in uterine flushings of P4treated ewes. The mechanism responsible for that effect is not known since P4 had been shown to increase expression of $O D C 1$ in female mice [52] and hamsters [53]. This study has also demonstrated that the protein expression of AGMAT and ODC in the LE is regulated by $\mathrm{P} 4$, suggesting that polyamine synthesis may be regulated by sex steroids in the ovine uterus.

In the present study, the most abundant amino acids in maternal plasma were glutamate, glycine, citrulline, 


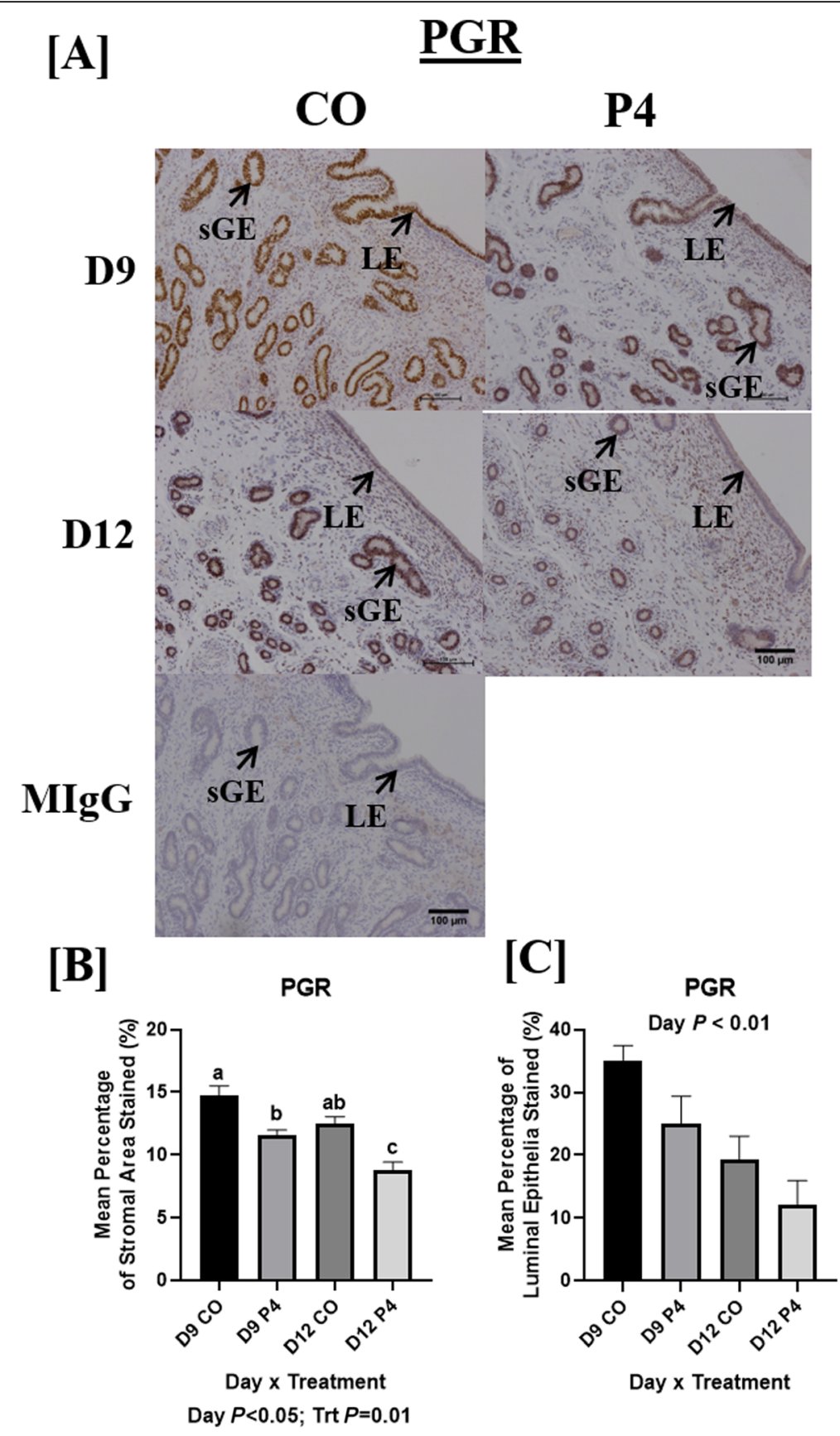

Fig. 7 Localization of endometrial PGR. PGR staining was most abundant in endometrial luminal epithelium (LE) and superficial glandular epithelia (sGE) in CO-treated ewes necropsied on day 9 of pregnancy and was markedly reduced in endometria of P4-treated ewes necropsied on day 9 and 12 (a and $\mathbf{b}$ ). Similar PGR localization and staining intensity was found in the LE of CO and P4-treated ewes necropsied on day 12. PGR in endometria of P4-treated ewes necropsied on day 12 was least abundant in both sGE and LE. Scale bar represents $100 \mu \mathrm{m}$. Only endometria from ewes which were considered pregnant with normally developed conceptuse were utilized for these analyses

arginine, alanine, valine, and leucine. Interestingly, concentrations of aspartate and citrulline were greater in the plasma of P4-treated than CO-treated ewes, we suggest that these two amino acids are precursors for arginine in the pathway responsible for synthesis of $\mathrm{NO}$ that increases angiogenesis and vasodilation to increase uterine blood flow during pregnancy $[54,55]$. Also, citrulline may be more effective than arginine for maintaining high concentrations of arginine in maternal and fetal blood as there are higher activity levels of arginase in mammalian tissues than enzymes responsible for degradation of citrulline [56]. Glutamate, serine, glycine, 
and taurine were the most abundant amino acids in uterine flushings in the present study which supports results of a previous study in which glycine, followed by serine, was the most abundant amino acid in uterine flushings from pregnant and cyclic ewes, but were in greater concentrations in pregnant ewes [35]. In contrast, glutamate was in lower concentrations in previous studies, although it was noted to increase 10 -fold between days 10 and 14 of pregnancy [35]. Increased concentrations of taurine in uterine flushings from P4treated ewes was an unexpected finding; however, considering that taurine is a very important antioxidant, osmoregulatory molecule, and regulator of the absorption of lipid soluble vitamins involved in growth and development of the conceptus this perhaps is not unexpected [57]. Concentrations of serine tended to be greater in uterine flushings from P4-treated than COtreated ewes in the present study suggesting increased substrate for one-carbon metabolism for production of thymidine, purines and $S$-adenosylmethionine, all of which are required for cellular functions supporting growth and development of the conceptus [58]. However, expression of mRNAs for the glycine transporter (SLC6A9) and the serine transporter (SLC1A4) were greater for CO-treated than P4-treated ewes on day 9 of gestation which is not consistent with no effect of treatment on the abundance of glycine and a slight increase in serine in uterine flushings from P4-treated ewes on day 12 of gestation. The basis for this lack of agreement is not known.

Results of this study confirm that FGF10 is a key progestamedin during the estrous cycle and early pregnancy [59] and is increased in response to P4 on day 9 of pregnancy [26]. P4-treated ewes had greater expression of FGF10 than CO-treated ewes on day 9 of gestation, but not on day 12 of pregnancy. We speculate that the exogenous P4 administration increased FGF10 expression on day 9 , which may partially account for accelerated development of ovine conceptuses in ewes treated with P4. Expression of FGF7 and $H G F$ was not affected by treatment of ewes with exogenous P4. FGF7 is only expressed in blood vessels and is not as highly expressed in ovine stromal cells as FGF10 [25], therefore, changes in expression of FGF7 in total homogenized endometrial tissues are difficult to detect. The expression of HGF by uterine stromal cells may be constitutive as it was not affected by $\mathrm{P} 4$ in the present study or in a previous study in our laboratory [26].

\section{Conclusions}

In conclusion, results of this study indicate that exogenous P4 treatment increased expression of the mitogen FGF10, which likely is responsible for the proliferation of trophectoderm cells prior to implantation of the conceptus. Additionally, exogenous P4 treatment decreased endometrial expression of AZIN2 for synthesis of polyamines, as well as endometrial glycine and serine transporters involved in one carbon metabolism. These findings suggest that while progesterone may accelerate conceptus development, its role in the mechanisms of implantation and pregnancy is complex and warrants further research to investigate its therapeutic properties in livestock reproduction.

\section{Supplementary Information}

The online version contains supplementary material available at https://doi. org/10.1186/s40104-021-00554-6.

Additional file 1. Table S1. Primer sequences designed for $\mathrm{QPCR}$ analyses.

\section{Abbreviations}

ANOVA: Analysis of variance; ATP: Adenosine triphosphate; CO: Corn oil; CL: Corpus luteum; Ct: Cycle threshold; GE: Uterine glandular epithelia; HPLC: High performance liquid chromatography; ICM: Inner cell mass; IFNT: Interferon-tau; LE: Uterine luminal epithelial epithelia; LSM: Least square means; NO: Nitric oxide; OPA: o-Phthaldialdehyde; RIN: RNA integrity number; P4: Progesterone; SC: Stromal cells; SEM: Standard error of the mean; sGE: Uterine superficial glandular epithelia; Tr: Trophectoderm; qPCR: Quantitative polymerase chain reaction

\section{Acknowledgements \\ The contributions of undergraduate students, graduate students, postdoctoral research associates, and faculty of Texas A\&M University to this study are gratefully acknowledged. The authors would also like to thank the animal research unit staff for their assistance.}

\section{Authors' contributions}

The experiments were planned by FB, GW, and GJ and executed by $\mathrm{EH}$ with assistance from $\mathrm{KH}, \mathrm{CS}, \mathrm{RM}, \mathrm{KD}, \mathrm{MS}$, and HS. The first draft of the manuscript was written by EH and FWB and was edited by GW, GJ, MS, CS, KH, and RM. The final version of the manuscript was prepared by EH and FWB. The authors read and approved the final manuscript.

\section{Funding}

This research was supported by Agriculture and Food Research Initiative Competitive Grant no. 2016-67015-24958 from the USDA National Institute of Food and Agriculture.

\section{Availability of data and materials}

The datasets generated in the current study can be made available from the corresponding author upon reasonable request.

\section{Ethics approval and consent to participate}

All experimental procedures followed the Guide for the Care and Use of Agriculture Animals in Research and Teaching and approved by the Institutional Animal Care and Use Committee of Texas A\&M University. There was no use of human participants, data, or tissues.

\section{Consent for publication}

Not applicable.

\section{Competing interests}

The authors have no conflict of interest to declare.

\section{Author details}

${ }^{1}$ Departments of Animal Science, Texas A\&M University, College Station, TX 77843-2471, USA. Veterinary Integrative Biosciences, Texas A\&M University, College Station, TX 77843, USA. 
Received: 7 October 2020 Accepted: 11 January 2021 Published online: 05 March 2021

\section{References}

1. Spencer TE, Johnson GA, Bazer FW, Burghardt RC. Implantation mechanisms: insights from the sheep. Biol Reprod. 2004;128:657-68.

2. Spencer TE, Bazer FW. Biology of progesterone action during pregnancy recognition and maintenance of pregnancy. Front Biosci. 2002;7:1879-98.

3. Bazer FW, Song G, Kim J, Dunlap KA, Satterfield MC, Johnson GA, et al. Uterine biology in pigs and sheep. J Anim Sci Biotechnol. 2012;3:23.

4. Nancarrow CD. Embryonic mortality in the ewe and doe In: Zavy MT, Geisert RD (eds.) Embryonic Mortality in Domestic Species. Boca Raton: CRC Press; 1994. p. 79-97.

5. Diskin MG, Morris DG. Embryonic and early Foetal losses in cattle and other ruminants. Reprod Dom Anim. 2008;43:260-7.

6. Dixon A, Knights M, Winkler J, Marsh D, Pate J, Wilson M, et al. Patterns of late embryonic and fetal mortality and association with several factors in sheep. J Anim Sci. 2007;85:1274-84

7. Casida LE, Warwick EJ. The necessity of the corpus luteum for maintenance of pregnancy in the ewe. J Anim Sci. 1945:4:34-6.

8. Wintenberger-Torrés S, Fléchon JE. Ultrastructural evolution of the trophoblast cells of the pre implantation sheep blastocyst from day 8 to day 18. J Anat. 1974;118:143-53.

9. Wilson ME, Lewis GS, Bazer FW. Proteins of ovine blastocyst origin. Proc Soc Study Reprod. 1979:11-21.

10. Eley RM, Thatcher WW, Bazer FW. Hormonal and physical changes associated with bovine conceptus development. Reprod. 1979;55:181-90.

11. Godkin JD, Bazer FW, Moffatt J, Sessions F, Roberts RM. Purification and properties of a major, low molecular weight protein released by the trophoblast of sheep blastocysts at day 13-21. Reprod. 1982;65:141-50.

12. Godkin JD, Bazer FW, Thatcher WW, Roberts RM. Proteins released by cultured day 15-16 conceptuses prolong luteal maintenance when introduced into the uterine lumen of cyclic ewes. J Reprod Fertil. 1984;71: 57-64.

13. Martal J, Lacroix MC, Loudes C, Wintenberger-Torres S. Trophoblastin, an antiluteolytic protein present in early pregnancy in sheep. J Reprod Fertil. 1979:56:63-73

14. Spencer TE, Johnson GA, Burghardt RC, Bazer FW. Progesterone and placental hormone actions on the uterus: insights from domestic animals. Biol Reprod. 2004;71:2.

15. Bazer FW. Uterine protein secretions: relationship to development of the conceptus. J Anim Sci. 1975;41:1376.

16. Bazer FW, Roberts RM, Thatcher WW. Actions of hormones on the uterus and effect on conceptus development. J Anim Sci. 1979;49:35-45.

17. Roberts RM, Bazer FW. The functions of uterine secretions. J Reprod Fertil. 1988:82:875-92.

18. Spencer TE, Bazer FW. Temporal and spatial alterations in uterine estrogen receptor and progesterone receptor gene expression during the estrous cycle and early pregnancy in the ewe. Biol Reprod. 1995;53:1527-43.

19. Lonergan P, Woods A, Fair T, Carter F, Rizos D, Ward F, et al. Effect of embryo source and recipient progesterone environment on embryo development in cattle. Reprod Fertil Dev. 2007;19:861-8.

20. Carter F, Forde N, Duffy P, Wade M, Fair T, Crowe MA, et al. Effect of increasing progesterone concentration from day 3 of pregnancy on subsequent embryo survival and development in beef heifers. Reprod Fertil Dev. 2008;20:368-75.

21. Garrett JE, Geisert RD, Zavy MT, Morgan GL. Evidence for maternal regulation of early conceptus growth and development in beef cattle. J Reprod Fertil. 1988;84:437-46.

22. Satterfield MC, Bazer FW, Spencer TE. Progesterone regulation of preimplantation conceptus growth and galectin 15 (LGALS15) in the ovine uterus. Biol Reprod. 2006;75:289-96.

23. Kleemann DO, Walker SK, Seamark RF. Enhanced fetal growth in sheep administered progesterone during the first three days of pregnancy. J Reprod Fertil. 1994;102:411-7.

24. Bazer FW, Spencer TE, Johnson GA. Interferons and uterine receptivity. Semin Reprod Med. 2009:27:90-102.

25. Chen C, Spencer TE, Bazer FW. Fibroblast growth factor-10: a stromal mediator of epithelial function in the ovine uterus. Biol Reprod. 2000;63: 959-66.
26. Satterfield MC, Hayashi K, Song G, Black SG, Bazer FW, Spencer TE. Progesterone regulates FGF10, MET, IGFBP1, and IGFBP3 in the endometrium of the ovine uterus. Biol Reprod. 2008;79:1226-36.

27. Niranjan B, Buluwela L, Yant J, Perusinghe N, Atherton A, Phippard D, et al. HGF/SF: a potent cytokine for mammary growth, morphogenesis and development. Development. 1995;121:2897-908.

28. Ohmichi H, Koshimizu U, Matsumoto K, Nakamura T. Hepatocyte growth factor (HGF) acts as a mesenchyme-derived morphogenic factor during fetal lung development. Development. 1998;125:1315-24.

29. Gao H, Wu G, Spencer TE, Johnson GA, Bazer FW. Select nutrients in the ovine uterine lumen. II. Glucose transporters in the uterus and periimplantation conceptuses. Biol Reprod. 2009;80:94-104.

30. Satterfield MC, Gao H, Li X, Wu G, Johnson GA, Spencer TE, et al. Select nutrients and their associated transporters are increased in the ovine uterus following early progesterone administration. Biol Reprod. 2010;82: 224-31.

31. Satterfield MC, Song G, Kochan K, Riggs P, Simmons R, Elsik C, et al. Discovery of candidate genes and pathways in the endometrium regulating ovine blastocyst growth and conceptus elongation. Physiol Genomics. 2009; 39:85-99.

32. Wu G, Morris SM. Arginine metabolism: nitric oxide and beyond. Biochem J. 1998;336(Pt 1):1-17.

33. Flynn NE, Meininger CJ, Haynes TE, Wu G. The metabolic basis of arginine nutrition and pharmacotherapy. Biomed Pharmacother. 2002;56:427-38.

34. Wu G, Bazer FW, Cudd TA, Meininger CJ, Spencer TE. Maternal nutrition and fetal development. J Nutr. 2004;134:2169-72.

35. Gao H, Wu G, Spencer TE, Johnson GA, Li X, Bazer FW. Select nutrients in the ovine uterine lumen. I. Amino acids, glucose, and ions in uterine lumenal flushings of cyclic and pregnant ewes. Biol Reprod. 2009;80:86-93.

36. Wang X, Burghardt RC, Romero JJ, Hansen TR, Wu G, Bazer FW. Functional roles of arginine during the peri-implantation period of pregnancy. III. Arginine stimulates proliferation and interferon tau production by ovine trophectoderm cells via nitric oxide and polyamine-TSC2-MTOR signaling pathways. Biol Reprod. 2015;92:1-17.

37. Wu G. Amino acids: biochemistry and nutrition. Boca Raton CRC Press; 2013 354-355.

38. Chattopadhyay MK, Tabor CW, Tabor H. Polyamines protect escherichia coli cells from the toxic effect of oxygen. Proc Natl Acad Sci U S A. 2003;100: 2261-5.

39. Fozard JR, Part ML, Prakash NJ, Grove J, Schechter PJ, Sjoerdsma A, et al. Ornithine decarboxylase: an essential role in early mammalian embryogenesis. Science. 1980;208:505-8.

40. Kwon H, Wu G, Bazer FW, Spencer TE. Developmental changes in polyamine levels and synthesis in the ovine conceptus. Biol Reprod. 2003;69:1626-34.

41. Lefèvre PLC, Palin MF, Murphy BD. Polyamines on the reproductive landscape. Endocr Rev. 2011;32:694-712.

42. Wang X, Ying W, Dunlap KA, Lin G, Satterfield MC, Burghardt RC, et al. Arginine decarboxylase and agmatinase: an alternative pathway for de novo biosynthesis of polyamines for development of mammalian conceptuses. Biol Reprod. 2014;90:1-15.

43. Seo H, Bazer FW, Burghardt RC, Johnson GA. Immunohistochemical examination of trophoblast syncytialization during early placentation in sheep. Int J Mol Sci. 2019;20:4530.

44. Lenis YY, Johnson GA, Wang X, Tang WW, Dunlap KA, Satterfield MC, et al. Functional roles of ornithine decarboxylase and arginine decarboxylase during the peri-implantation period of pregnancy in sheep. J Anim Sci Biotechno. 2018:9:1-13.

45. Scarpa JO, O'Neil MM, Cardoso RC, Stanko RL, Williams GL. Ovarian follicular and luteal characteristics in Bos indicus-influenced beef cows using prostaglandin F 2 a with or without GnRH at the onset of the 5-day COsynch + controlled internal drug release (CIDR) protocol. Anim Reprod Sci. 2019;204:1-9.

46. Vermeulen J, Derveaux S, Lefever S, Smet ED, Preter KD, Yigit N, et al. RNA pre-amplification enables large-scale RT-qPCR gene-expression studies on limiting sample amounts. BMC Res Notes. 2009;2:1-9.

47. Gao H, Wu G, Spencer TE, Johnson GA, Bazer FW. Select nutrients in the ovine uterine lumen. III. Cationic amino acid transporters in the ovine uterus and peri-implantation conceptuses. Biol Reprod. 2009:80:602-9.

48. Kwon HST, Bazer FW, Wu G. Developmental changes of amino acids in ovine fetal fluids. Biol Reprod. 2003:68:1813-20.

49. Inc SI. SAS. In: SAT/STAT User's Guide, 6th ed ed. Gary, NC; 1992. 
50. Lonergan P, Jose C, Sanchez M, Mathew DJ, Passaro C, Fair T. Embryo development in cattle and interactions with the reproductive tract. Reprod Fertil Dev. 2019;31:118-25.

51. Gao H, Wu G, Spencer TE, Johnson GA, Bazer FW. Select nutrients in the ovine uterine lumen V. nitric oxide synthase, GTP cyclohydrolase, and ornithine decarboxylase in ovine uteri and peri-implantation conceptuses. Biol Reprod. 2009;81:67.

52. Bastida CM, Cremades A, Castells MT, López-Contreras AJ, López-García C, Tejada F, Peñafiel R. Influence of ovarian ornithine decarboxylase in folliculogenesis and luteinization. Endocrinology. 2005;146:666-74.

53. Luzzani F, Colombo G, Galliani G. Evidence for a role of progesterone in the control of uterine ornithine decarboxylase in the pregnant hamster. Life Sci. 1982;31:1553-8.

54. Wu G, Bazer FW, Satterfield MC, Li X, Wang X, Johnson GA, et al. Impacts of arginine nutrition on embryonic and fetal development in mammals. J Amino Acids. 2013:45:241-56.

55. Sooranna SR, Morris NH, Steer PJ. Placental nitric oxide metabolism. Reprod Fertil Dev. 1995;7:1525-31.

56. Lassala A, Bazer FW, Cudd TA, Li P, Li X, Satterfield MC, Spencer TE, Wu G. Intravenous administration of $\mathrm{L}$-citrulline to pregnant ewes is more effective than $\mathrm{L}$-arginine for increasing arginine availability in the fetus. J Nutr. 2009; 139:660-5.

57. Wu G. Important roles of dietary taurine, creatine, carnosine, anserine and 4hydroxyproline in human nutrition and health. Amino Acids. 2020;52:329-60.

58. Brosnan ME, Brosnan JT. Formate: the neglected member of one-carbon metabolism. Annu Rev Nutr. 2016:36:369-88.

59. Chen C, Spencer TE, Bazer FW. Expression of hepatocyte growth factor and its rececptor c-met in the ovine uterus. Biol Reprod. 2000:62:1844-50.

Ready to submit your research? Choose BMC and benefit from:

- fast, convenient online submission

- thorough peer review by experienced researchers in your field

- rapid publication on acceptance

- support for research data, including large and complex data types

- gold Open Access which fosters wider collaboration and increased citations

- maximum visibility for your research: over $100 \mathrm{M}$ website views per year

At $\mathrm{BMC}$, research is always in progress.

Learn more biomedcentral.com/submissions 